\title{
A CRECHE ENQUANTO CONTEXTO POSSIVE DE DESENVOLVIMENTO DA CRIANÇA PEQUENA
}

\section{THE CRÈCHE AS A POSSIBLE CONTEXT OF DEVELOPMENT FOR THE CHILD}

ROSSETTI-FERREIRA, M. C., AMORIM, K. S.; VITÓRIA, T. A Creche enquanto Contexto Possive1 de Desenvolvimento da Criança Pequena. Rev. Bras. Cresc. Des. Hum., São Paulo, IV(2), 1994.

Resumo: O artigo apresenta uma visão compacta da situac,ão atual das creches no Brasil. Compara-a com a de outros países, argumentando a favor da urgente necessidade de pesquisas neste campo. Apresenta um projeto, ainda em desenvolvimento, sobre os processos de adapta,cão de bebês e de suas famílias quando ingressam na creche, considerando-os como resultantes de múltiplos fatores (biológicos, psicossociais e históricos do bebe, da família e da creche). Ilustra com um dos subprojetos, cujo objetivo é investigar o papel mediador dos adulto (pais e educadoras de creche), em relação aos bebês, na apresentação das novas pessoas e situações.

Palavras-chave: creche, adaptação, bebês, desenvolvimento e mediação.

Summay: The paper presents a brief vision of the current state of the day care centers in Brazil. While comparing it with that of other countries, it emphasizes the urgent need of research in this arca. It presents a project, yet in progress, about the adaptation of babies and their families when they start attending a crèche. The adaptation process is considered as resulting from multiple biological, psychosocial and historical factors of the family and of the institution. One of the subprojects is illustrated; it intends to investigate the mediation role of adults when introducing the baby to the new persons and situations.

Key-words: creche, adaptation, babies, mediation and development.

1 Prof Titular da Fac. Fil. Ciências e Letras de Ribeirão Preto-USP e Coordenadora do Centro Brasileiro de Investiga õe:s sobre Desenvolvimento e Educação infantil (CINDEDI).

2 Mestranda na Área de Psicologia da FFCLRP-USP.

3 Mestranda na Área de Saúde Mental da Faculdade de Medicina de Ribeirão Preto-USR END: Av. Bandeirantes 3.900, Ribeirão Preto - SP, CEP 14040-030 Fone: (016) 633.1010 r. 374 Fax: 623.2792 
A creche constitui-se palco interessante para estudo, já que vem se tornando uma necessidade significativa da população. Isso surge como consequência das transformações sócio-econômicas que a sociedade vem sofrendo, com as alterações nos modos de relações entre os indivíduos, além de mudanças no exercício das funções, em especial aquelas realizadas pelas mulheres. Essas passam, cada vez mais, a trabalhar fora de casa, motivadas pela necessidade de contribuir com a sobrevivência da família, ou pelo desejo de realização profissional, entre outros. Associado a isso, a migração em larga escala de populações rurais para centros urbanos industrializamos, a diminuição no número de elementos da família, a quebra na rede de apoio familiar e de vizinhança e um distanciamento físico e psicológico entre os diferentes membros (irmãos, tios, avós...) levam à procura de soluções para os cuidados da criança, complementares à mãe, fora do espaço familiar. Mesmo as mulheres que não trabalham fora têm procurado um espaço de socialização para as crianças, já que hoje contam com poucos recursos no espaço doméstico. Essas formas têm sido encontradas em diferentes níveis, através de creches, escolinhas berçários, creches domésticas...

Nesse contexto, duas questões mostramse especialmente relevantes e conflitantes: a função da maternidade e a educação de crianças, especialmente nos primeiros anos de vida, em ambientes coletivos.

A concepção que prevalece em nossa sociedade é a de que o único cuidado capaz de prover condições adequadas ao desenvolvimento do bebê é aquele provido pela mãe no contexto da família. Assume-se o modelo de criação na família nuclear, constituída por mãe, pai, filhos e parentes mais próximos, como "natural", isto é, requerido por características próprias do ser humano.

Contextos de desenvolvimento diversos, como 0 cuidado coletivo de crianças pequenas em creche, são encarados como “mal necessário”, por constituírem um risco ao desenvolvimento sadio da criança e aceitáveis apenas naqueles casos em que a mãe ou a família não tem condições de criar o filho em casa. Contudo, essa visão vem sendo contestada especialmente a partir de estudos que procuram demonstrar de que maneira ela se encontra influenciada por práticas, concepções e valores sociais, constituídos historicamente.

O exercício da maternidade nos moldes como conhecemos hoje, segundo autores como ARIES (1978); BADINTER (1985) e POSTER (1979), é relativamente recente na história da humanidade. As mudanças estão intimamente associadas às transformações econômicas e sociais que ocorreram através das épocas nas várias sociedades e, em particular, na família Assim, a estrutura de certas sociedades ou grupos sociais promove um cuidado mais com- partilhado das crianças pequenas, com crianças mais velhas, adolescentes e adultos, com ou sem grau de parentesco, colaborando nesta tarefa. Já na sociedade ocidental capitalista predomina o modelo de família nuclear, com uma frequiência cada vez maior de mães e/ou pais solteiros ou descarados, famílias agregadas com filhos de diferentes casamentos, famílias com filhos adotivos, famílias de homossexuais, dentre outros.

Há grandes diferenças também na forma como o Estado concebe a responsabilidade pela educação da criança. Por um lado temos países como os Estados Unidos e a Inglaterra, que atribuem essa função exclusivamente à família, assumindo-a apenas com a conotação de mal necessário, acima descrita. Já os Países Escandinavos, a Austrália, a Nova Zelandia e Israel, assim como alguns países ex-socialistas como a Hungria, por exemplo, propõem que essa responsabilidade deva ser compartilhada entre as famílias e o Estado. No Brasil, têm havido, nas últimas décadas, importantes transformações, fruto da luta de vários profissionais e associações, inclusive das próprias famílias requerendo do Estado e de Organizações não Governamentais (ONGs) um auxílio de qualidade na educação de seus filhos. Através dessas lutas conseguiu-se que, na Constituição Nacional de 1988, o atendimento às crianças de $0 \mathrm{a} 6$ anos fosse incluído no capítulo da Educação, sendo definido como um direito da criança, um dever do Estado e uma opção da família, tirando-lhe assim a conotação meramente assistencial, típica dos momentos anteriores.

É interessante notar como essas formas de organização social e econômica são referendadas por ideologias específicas, as quais frequentemente norteiam as pesquisas científicas feitas nos vários países. Assim, na sociedade americana e inglesa predominam as pesquisas e discussões a respeito dos efeitos perniciosos da frequência à creche sobre o desenvolvimento social e emocional da criança pequena, particularmente em seus primeiros anos de vida (FOX \& FEIN, 1990). Partem da noção de que, por natureza, o bebe humano requer o cuidado em casa pela mãe, não sendo adequados outros contextos para ele se desenvolver satisfatoriamente. Fundamentados na teoria do apego de Bowlby, ROSSETIFERREIRA (1984) mostra através de uma revisão bibliográfica que tais estudos usam, em geral, o paradigma da "situação estranha" de AINSWORTH et ai (1978) a fim de demonstrar as alterações provocadas pela freqüência precoce à creche, tanto nas relações de apego criança-mãe como no comportamento da criança, a qual se mostraria menos cordas "compliant" e mais agressiva na pré-escola. Os resultados dessas pesquisas têm sido contraditórios e não conclusivos vos (FOX \& FEIN, 1990). 
Já os Países Escandinavos, a Austrália e alguns centros na França, Itália, Israel e mesmo no Brasil, reconhecendo a diversidade de ambientes, de necessidades e de formas de relações que mesmo as crianças pequenas vivenciam em seu cotidiano, preocupam-se mais em investigar como promover um atendimento de qualidade em creches em seus vários aspectos (CRESAS, 1991; FIORANI \& MUSAITI, 1986; MANTOVANI \& TERZI, 1987; PRAMLING \& LINDAHL, 1992).

Em diversos países, como no Brasil, a creche desempenhou, através dos anos, atividades com caráter predominantemente assistencialista e filantrópico de combate à pobreza e à mortalidade infantil, envolvendo situações de grande miséria e desestruturação familiar. A rotina de funcionamento da maioria das creches centrava maior atenção na guarda e nos cuidados físicos da criança, não na educação e na busca de um adequado desenvolvimento global. Essa história persiste na consciência da coletividade e dá à creche um caráter que, muitas vezes, não Ihe cabe mais, visto que as várias classes sociais, passam a considerá-la como alternativa, especialmente para as crianças acima de 2-3 anos.

Entretanto, a estrutura básica de funcionamento da creche, ainda arraigada aos moldes de sua função assistencial anterior, conflito com um conjunto de valores que hoje a sociedade neoliberal professa, definido pela busca de identidade, individualidade e intimidade. Tais valores podem ser percebidos como inatingíveis em uma situação de creche, onde o espaço físico e os brinquedos são comuns, sem a possibilidade de garantia de posses ou privacidade; as atividades são compartilhadas pelas diferentes crianças; momentos culturalmente considerados íntimos, como o banho e a amamentação, passam a se realizar publicamente, devendo o decoro e a sexualidade ser reavaliados.

A indefinição quanto ao papel social e educacional da creche é marcante, o que resulta em influências sobre os elementos que nela trabalham e que dela se beneficiam. Muitas creches, por exemplo, propõem-se a uma atuação enquanto "substituia” da mãe, o que, além de ser impossível, acentua nos pais o temor de que a criança goste mais das educadoras e do novo ambiente. Na educadora, por sua vez, é induzida uma postura crítica em relação às mães e a seu exercício da maternidade.

No tradicional modelo de educação, a criança é formada pelo adulto, através das atividades e interações que desenvolve com ela. Esse falo também conflita com a estrutura da creche, onde a proporção adulto-criança é baixa e o parceiro mais disponível para interação são outras crianças. Assim, os pais, muitas vezes, têm a impressão de falta de cuidados apropriados a cada criança individualmente. Ademais, essa maior interação com outras crianças pode ser vista como perigosa em termos de "influência” e de possível prejuízo à integridade física dos filhos.

Esses vários elementos, associados a algumas características de ordem institucional, além da frequente má formação do profissional de creche, tendem a conduzir os familiares, que optam por esse tipo de educação para seus filhos, a uma situação de profunda ambivalência e convergem num questionamento sobre a capacidade da creche de cuidar e educar crianças pequenas. Seria ingênuo, portanto, tratar o dilema destas famílias de uma forma puramente psicológica e/ou individual.

O desafio a ser enfrentado pelos profissionais da área envolve o desenvolvimento de pesquisas, programações e soluções que permitam promover um atendimento de qualidade, o qual deve contemplar a função social em relação à população que atende, além dos objetivos e princípios norteadores do trabalho educativo junto às crianças. Para tanto, as principais estratégias relacionamse à definição do papel profissional das educadoras, à melhora de suas condições de trabalho e ao incremento de sua formação inicial e em serviço. Ademais, um esforço de conhecimento e valorização da criança pequena, suas características e necessidades nesse novo contexto, buscando apreender a importancia da interação entre a mãe e o filho e de suas outras interações no novo ambiente, em particular o valor da interação criançacriança (OLIVEIRA \& ROSSEITI-FERREIRA, 1993), permitirá promover um desenvolvimento adequado à qualidade do atendimento hoje prestado na maioria das instituições.

O estudo da adaptação à creche vem no sentido de investigar um período crítico para todos os elementos envolvidos (beba, famílias e educadoras), pois implica num conjunto de reorganizações, numa época em que uma série de transformações pessoais e coletivas também se manifestam. A mãe, em especial a do primeiro filho, assumiu recentemente a função de mãe. Estão Ihe sendo reatribuídos novos significados, papéis e responsabilidades associados a um conjunto contraditório de regras e condições ditadas pelo meio, pelas necessidades emergenciais do beba, por suas experiências anteriores e pelas suas expectativas. O bebé? em um processo recente de adaptação às condições extra-uterinas, defronta-se também com a aquisição de novas competências, além da ampliação da rede de interações e da adaptação a novos espaços e rotinas.

A interação mãe-bebê sofre transformações ao passar do espaço domiciliar, onde havia uma maior intimidade e exclusividade, para uma situação onde há uma separação frequente da díade, o estabelecimento de novas relações e o fim da exclusividade de cuidadosrealizados por um familiar. Nesse contexto, há a introdução de novos parceiros, de um novo ambiente com novas rotinas. A educadora, que passa a realizar os cuidados da 
criança, também deve conhecê-la, já que há um conjunto de características pessoais dessa criança e família que são específicas e devem ser respeitadas, valorizadas e eventualmente modificadas. Elas próprias trazem suas experiências anteriores de maternidade, efetivadas ou não, de cuidados com filhos, além de um conjunto de conceitos culturais e expectativas quanto ao seu papel de educadora ou de funcionária na instituição.

Todo esse processo provoca inicialmente e com frequência, situações de grande tensão entre pais e educadoras, relacionadas aos conceitos de obrigações da maternidade e de educação dos filhos, geradoras de dúvida, angústia e culpa, apesar de representarem também um motivo de alegria, conquista ou alívio por se conseguir uma vaga na creche. De qualquer forma, os conceitos que trouxerem de sua experiência de vida, certamente estarão expressos em sua relação com a creche, na forma como vão introduzi-la às crianças e no significado que lhe será dado. Nesse momento desafiador para todos, o apoio aos esforços de adaptação certamente influenciará e será influenciado pelas reações da criança.

O desafio torna-se mais significativo quando se considera as características da criança em seu primeiro ano de vida. O bebe humano, por ser incapaz de sobreviver e interagir no mundo sem a ajuda e mediação de outros indivíduos mais experientes de sua espécie, apresenta um prolongado período de aprendizagem, provocando uma intensa união e desenvolvendo um forte vínculo afetivo em relação àqueles que com ele interagem e cuidam. Durante o primeiro ano de vida do bebé, o encontramos em um profundo estado de fusão emocional com o meio, confundindo-se com ele, sem capacidade de estabelecer distinção entre ambos, com uma forma sincrética e fusionada de perceber, sentir e reagir. Assim, através desse contato íntimo, com o adulto, o bebe apreende os significados apresentados e vivenciados pelos outros, como sendo dele próprio (WEREBE \& NADEL-BRULFERT, 1986).

Será, então, a partir desses significados vivenciados emocionalmente com os outros, num sistema de valores e conceitos compartilhados pelos adultos com seu grupo social em determinado contexto sócio-histórico, que a criança se desenvolverá, formando conceitos, adaptandose às diferentes situações, entrando em contato com a cultura do grupo, com seus próprios sentimentos e comportamentos. Isso significa que o seu desenvolvimento vai se dar através de um processo de construção social, nas e através das múltiplas interações que estabelece, desde o seu nascimento, com outras pessoas, e particularmente, com aquelas com as quais mantém um maior vínculo afetivo (OLIVEIRA et ai, 1992).
Essas interações ocorrem em ambientes sociais historicamente organizados, modificados pelo adulta conforme as concepções sobre desenvolvimento e edu cação infantil próprias daquela cultura, das quais ele $\wedge \mathrm{S}$ apropriou através de suas experiências anteriores. Assim cada pessoa interage com a criança e organiza seus am bientes, conforme as representações e expectativas que tem sobre ela, sobre seu desenvolvimento e sobre sei próprio papel com relação a ela. Vai ser através da me diação do meio, com a apresentação de significados que pouco a pouco, os signos existentes nessas atividade sociais variadas vão sendo incorporadas pela criança passam a se tornar mediadores simbolicos de sua relação com o mundo. A criança, no entanto, alua nesse process não como um sujeito passivo, simplesmente moldad pelo meio, mas como um ser ativo, que desempenha un papel importante nas interações (VYGOTSKY, 1984). criança tem, assim, a possibilidade de ser influenciada pelo meio e também de atuar sobre ele, transformando-o re-significando-o, numa construção mútua, onde, tanto criança, como o adulto, desenvolvem-se (WALLON 1966; VYGOTSKY, 1984).

\section{O PROJETO DE PESQUISA SOBRE O PROCESSO DE ADAPTAÇ̃̃O DE BEBÊS À CRECHE}

As experiências de pesquisa, de assessória e de formação de pessoal do Centro Brasileiro de Investigação sobre Desenvolvimento e Educação Infantil (CINDEDI) têm mostrado que, um bom trabalho de organização de um ambiente adequado às necessidades da criança, nos primeiros anos de vida e sua inserção e de suas famílias à creche, facilita o processo de adaptação da familia e da educadora responsável pela criança e um desenvolvimento harmonioso desta em seu grupo de convivência na creche (VITORIA \& ROSSETTI -FERREIRA, 1993).

Existem, entretanto, poucos estudos documentando e investigando como se dão esses processos de adaptação à creche, em especial, no que se refere à criança menor de dois anos.

O CINDEDI organizou, então, um estudo com o objetivo de registrar e analisar os processos de adaptação de bebes, seus familiares e as educadoras, durante os tres primeiros meses de frequência, com um seguimento menos intenso até o início do segundo ano na creche.

Várias pesquisas estão sendo desenvolvidas com os objetivos específicos de:

- investigar como o adulto (familiar e educadora), em suas interações com a criança, apresenta e significa as novas experiências na creche. Como a integra ao novo 
ambiente, aos novos objetos e pessoas, incluindo as outras crianças. Que significado atribui à ausência da mãe e familiares, ao falo da mãe não realizar os cuidados do filho e à presença de outros adultos que cuidarão dela no período de ausência da mãe;

- investigar longitudinalmente a construção das relações e o estabelecimento de vínculos entre a criança e suas educadoras e entre a criança e outras crianças do berçário e mini-grupo;

- investigar a construção e desenvolvimento de relações entre a mãe, o pai e outros familiares com as educadoras de seus filhos e com a creche, buscando verificar sua influência sobre as reações da criança durante o processo de adaptação;

- analisar eventuais alterações no estado de saúde das crianças e em seus hábitos alimentares, de sono e eliminação, durante o processo de adaptação, como uma possível resposta ao stress frente à separação dos familiares e ao ambiente e rotina novos que têm de enfrentar.

O estudo vem sendo desenvolvido na creche Carochinha, da USP de Ribeirão Preto. Essa creche existe há 10 anos, e atende as famílias que têm vínculo de trabalho ou estuda na Universidade. A admissão das crianças obedece a uma proporcionalidade, onde os funcionários ocupam $70 \%$ das vagas e os docentes, alunos graduandos e pós-graduandos, $10 \%$ cada.

Nesses 10 anos, a direção da creche, em associação com o CINDEDI, tem conseguido elaborar o papel social e pedagógico dessa instituição. Concebida como um local complementar ao cuidado da família, com quem compartilha a responsabilidade da educação da criança, ela oferece um contexto especialmente planejado para promover o desenvolvimento infantil. Organiza-se enquanto um espaço onde as interações das crianças são favorecidas, tanto com os adultos como com as outras crianças.

A creche Carochinha compreende a necessidade de que o processo de adaptação ocorra da forma mais adequada possível para a criança e sua família. Nessa fase; programa cuidadosamente o ingresso das crianças e das famílias à creche, de forma a promover o conhecimento e confiança mútua, favorecendo assim a integração e o estabelecimento de vínculos entre eles e as educadoras. A inserção é feita, progressivamente, duas crianças por semana, cada criança iniciando em um período do dia (manhã/tarde), o que dá às educadoras uma disponibilidade maior no atendimento ao bebé e sua família. Num periodo variando entre uma a duas semanas, os familiares são solicitados a permanecerem junto à criança na creche. $\mathrm{O}$ tempo de permanência vai aumentando e os pais são orientados a afastarem-se progressivamente, até o bebe poder ficar sem eles o período integral.
Visando a efetivação do estudo, a equipe realizou reuniões com a direção da creche, com as educadoras e com as famílias, apresentou-lhes o projeto e obteve as autorizações para a realização das entrevistas, observações, gravações em vídeo e áudio. Foram organizadas fichas de identificação das crianças e suas famílias (tipo anamnese), fichas de frequência, estado de saúde, intercorrências médicas e observação da criança. Foram realizadas entrevistas inicialmente semanais e depois quinzenais com as educadoras e os técnicos, além de algumas entrevistas com as mães, a fim de acompanhar o processo de adaptação e verificar as reações da criança no reinício do segundo ano de frequência.

Os sujeitos do estudo foram 18 bebés do berçário e 8 do rnini-grupo, que começaram gradualmente a freqüentar a creche em março-abril de 1994, com seus familiares e as respectivas educadoras. Um subgrupo de 8 bebas (2 de cada grupo de berçario e do mini-grupo), considerados como sujeitos focais, foram investigados mais de perto, com observações mais frequentes.

Partindo dos mesmos referênciais teóricos, cada pesquisados concentra seu trabalho em um tipo de dado coletado (áudio, audiovisual ou registros) e os demais são utilizados de forma complementar, permitindo também mútuas influências entre os subprojetos. A metodologia de análise de cada subprojeto varia conforme o objetivo proposto. Para o estudo do processo de mediação realizado pelo adulto, por exemplo, conforme proposto no primeiro objetivo, a análise baseou-se mais especificamente nas gravações em vídeo. As fitas das entrevistas realizadas com as educadoras e famílias estão sendo utilizadas no sentido de complementar as observações realizadas. As gravações foram condensadas em fitas individualizavas, relativas aos "sujeitos-focais" e estruturadas de forma cronológica, desenvolvendo sua história de adaptação. Observamos, então, as diversas situações, identificamos episódios, procurando explicitar os momentos em que ocorrem as situações de mediação por parte dos adultos. Essa observação tem se dado de forma muito especial, visto os bebas apresentarem uma comunicação basicamente não verbal, interagindo através de olhares, posturas, choras, movimentos corporais, ritmos, vocalizações, sorrisos... Neles, a emoção funciona como o grande motor da interação. A isso o adulto busca ajustarse, apresentando e interpretando as situações, de forma verbal e não verbal. Assim, aprende a captar os sinais emitidos pela criança, atribuindo-lhes significados. A linguagem surge como inerente à condição desses adultos, acompanhando ou não, a comunicação não verbal, sendo coerente ou não com ela. Ademais, a fala é utilizada para desenvolver a linguagem como meio de comunicação na criança. Os gestos e posturas tornam-se, então, os 
recortes das situações interativas, veículos de significação.

Essa trama de alterações nos equilíbrios, a adaptação a novos momentos e as interações entre os elementos estão sendo buscados. Compreendese que esses se tratam de processos, significando uma sucessão de estados ou mudanças, num sistema dinâmico, que se transforma continuamente.

Esperamos que esta investigação possa desempenhar uma função social importante, na medida em que seus resultados poderão contribuir para o trabalho de formação do educador, agente fundamental para o processo de adapta-

\section{BIBLIOGRAFIA}

AINSWORTH, M. D. S.; BLEHAR, M. C.; WATERS, E.; WALL, S. Patterns of attachment. New Jersey, Lawrenee Erlbaun Associates, 1978.

ARIES, R História social da criança e da família. Rio de Janeiro, Ed. Guanabara Koogan, 1978.

BADINTER, E. Um amor conquistado: o mito do amor materno. Rio de Janeiro, Ed. Nova Fronteira, 1985. CRESAS Accueillir à la crèche, à l'école. INRP, L'Harmattan,1991.

FIORANI, A.; MUSATTI, T. L'inserimento del bambino al nido e il processo di socializzazione tra coetanei. In: MUSATTI, T.; MANTOVANI, S. (ed.) Stare insieme ah nido: relazioni sociali e interventi educativi. Juvenilia, 1986.

FOX, N.; FEIN, G. G. (ed.) Infant day care: lhe current debate. New Jersey, Norwood, 1990.

MANTOVANI, S.; TERZI, N. L'inserimento. In BONDOLI, A.; MANTOVANI, S. (ed.) Manuale critico dell' asilo nido. Milano, Franco Angeli, 1987. ção e de educação dessas crianças. Além disso, poderá também fornecer subsídios para uma organização do espaço físico da creche e do planejamento pedagógico que, se sistematizados, permitirão melhores condições para o desenvolvimento integral da criança.

\section{AGRADECIMENTOS}

As autoras agradecem financiamento da FAPESP, CAPES e CNPq a este projeto de pesquisa.

OLIVEIRA, Z. M. R.; ROSSETTI-FERREIRA, M. C. O valor da interação criança-criança em creches no desenvolvimento infantil. Cad. Pesq., 87:62-70, 1993.

OLIVEIRA, Z. M. R. et ai. Creches: faz de conta \& cia. Petrópolis Ed. Vozes, 1992.

POSTER, M. Teoria crítica da família. Rio de Janeiro, Ed. Zahar, 1979.

PRAMLING, I.; LINDAHL, M. Entering lhe world of day-care. Paper presented at lhe Vth European Conference on Child Development, Seville, Spain, 1992.

ROSSETTI-FERREIRA, M. C. O apego e as reações da criança à separaçãodamãe: uma revisãobibliográfica. Cad Pesq., 48:3-19 1984.

VITORIA, T.; ROSSETTI-FERREIRA, M. C. Processos de adaptação na creche. Cad Pesq., 86:55-64, 1993.

VYGOTSKY, L. S. A formação social da mente. São Paulo, Ed. Martins Fontes, 1984.

WALLON, H. Do acto ao pensamento. Porto Alegre, Ed. Porto Calia, 1966

WEREBE, M. J. G.; NADEL-BRULFERT, J. Henri Wallon. S Paulo, Ed. Ática, 1986.

recehido em: 20/04/95 aprovado em: 10/05/95 